\title{
Educação CTS: Parâmetros e Propósitos Brasileiros
}

\section{STS Education: Brazilian Parameters and Educational Purposes}

\author{
Roseline Beatriz Strieder ${ }^{a}$; Maria Regina Dubeux Kawamura ${ }^{b}$ \\ a Instituto de Física, Universidade de Brasília, Brasília, Brasil - roseline@unb.br \\ b Instituto de Física, Universidade de São Paulo, São Paulo, Brasil - mrkawamura@if.usp.br
}

Palavras-chave:

Ciência-TecnologiaSociedade. Educação científica. Educação CTS.

\section{Keywords:}

Science-Technology-

Society. Science education. STS.
Resumo: Neste artigo são discutidos parâmetros e propósitos da educação ciênciatecnologia-sociedade (CTS), presentes no contexto brasileiro do ensino de Ciências. Os mesmos resultam do cruzamento de informações oriundas do estudo de referenciais teóricos, pertencentes aos campos da ciência, tecnologia, sociedade, educação e ensino de Ciências, e da aproximação a trabalhos sobre CTS, publicados em revistas e eventos da área de Ensino de Ciências no Brasil. Os parâmetros da educação CTS referem-se à racionalidade científica, desenvolvimento tecnológico e participação social. Os propósitos educacionais associam-se ao desenvolvimento de percepções, questionamentos e compromissos sociais. A identificação e caracterização desses parâmetros e propósitos possibilitam reconhecer diferentes abordagens a serem contempladas no âmbito da educação CTS; o que, além de permitir uma compreensão maior e mais clara sobre os sentidos e perspectivas da educação científica CTS no Brasil, contribui para a seleção de elementos a serem priorizados em práticas escolares. 


\section{Introdução}

O movimento ciência-tecnologia-sociedade (CTS) teve origem em meados do século $\mathrm{XX}$ em diferentes partes do mundo, merecendo destaque as reflexões desenvolvidas na América do Norte, Europa e América Latina. Como motivações desse movimento, têm sido mencionados, dentre outros, a insatisfação em relação à concepção tradicional da ciência e da tecnologia, os problemas políticos e econômicos relacionados ao desenvolvimento científico e tecnológico e à degradação ambiental, o modelo linear de desenvolvimento e, associado a isso, a busca por novas maneiras de compreender o próprio desenvolvimento científicotecnológico (GARCÍA et al., 1996).

Em especial, no que se refere à América Latina, vale ressaltar que as discussões CTS fazem parte do que Dagnino et al. (2003) denominam por Pensamento Latino-Americano em CTS (PLACTS). O PLACTS caracteriza-se não somente por questionar as consequências sociais do desenvolvimento científico-tecnológico ou seus antecedentes, mas, principalmente, por criticar o modelo de política científico-tecnológica adotado nos países latino-americanos, baseado em países do chamado primeiro mundo e contrário às necessidades regionais.

Independente da vertente, europeia, norte-americana ou latino-americana, desde sua origem, os estudos CTS vêm se desenvolvendo tanto no campo acadêmico como nos campos das políticas públicas e da educação, que, apesar de diferentes, estão relacionados e influenciam-se (GARCÍA et al., 1996) ${ }^{1}$.

No que se refere ao campo educacional brasileiro, foco da presente investigação, a década de 1990 é entendida como um marco. De acordo com Santos (2008), ainda que alguns pesquisadores tenham mencionado anteriormente a importância de discussões sobre as relações CTS nos currículos de Ciências do Brasil (a exemplo de Krasilchick, 1987), foi na década de 1990 que tiveram início as primeiras pesquisas envolvendo essa temática, dentre essas, as realizadas por Santos (1992), Trivelato (1993), Amorin (1995), Cruz (2001) e Auler (2002).

Desde então, tem aumentado o interesse e as preocupações com abordagens CTS no ensino de Ciências, no Brasil, que vêm se expressando em relatos de trabalhos, comunicações em eventos da área, artigos em revistas ou teses e dissertações. A esse aumento no número de trabalhos, está associada uma maior diversidade de abordagens. Como consequência, várias pesquisas têm apontado a polissemia do campo CTS na educação científica, tanto em âmbito nacional quanto internacional, a exemplo de Martins (2000), Santos (2001), Auler e Bazzo

\footnotetext{
${ }^{1}$ García et al.. (1996), ao apresentar essa classificação não se referem à América Latina, contudo, a nosso ver, ela também cabe para esse contexto.
} 
(2001), Aikenhead (2003), Cachapuz et al. (2008), Hunsche et al. (2009), Strieder e Kawamura (2009, 2010), Santos (2011) Auler (2011) e Pedretti e Nazir (2011).

A nosso ver, essa polissemia pode estar relacionada aos espaços pedagógicos que o pesquisador encontra para desenvolver seu trabalho e não, propriamente, a sua compreensão sobre CTS. Encaminhamentos dados às atividades de ensino-aprendizagem e às discussões realizadas, também podem levar a propostas de diferentes naturezas, ainda que sempre envolvendo um ou mais dos três elementos da tríade CTS e/ou suas articulações. Também, a complexidade intrínseca às questões relacionadas à ciência, à tecnologia e à sociedade, certamente dificulta a implementação dos pressupostos do movimento CTS no contexto educacional. Qualquer discussão dessa natureza envolve uma série de variáveis que perpassam diferentes campos do conhecimento, além do científico (a exemplo do político, social, econômico, etc.), o que dá margem para uma série de recortes e, consequentemente, para a diversidade.

Diante desse quadro, é bastante improvável que possa haver uma compreensão única sobre como trabalhar tais questões, de forma articulada, sob um ponto de vista educacional. Sendo assim, a polissemia pode ser entendida como inerente ao movimento, refletindo a própria complexidade das questões envolvidas e, de certa forma, conferindo à educação CTS uma abrangência mais expressiva, abrindo um leque de possibilidades para a inserção de propostas dessa natureza nos diferentes níveis de ensino, como coloca Aikenhead (2003). Entendemos que as propostas de educação CTS têm diferentes valores implícitos e contribuições educacionais distintas, as quais, como afirma Santos (2001), não podem ser ignoradas ou subestimadas.

Essa abrangência, ainda que altamente positiva, muitas vezes dificulta o diálogo e o compartilhar das práticas, na medida em que nem sempre são explicitadas as dimensões educacionais propostas. Diante disso, torna-se relevante indagar em que sentido as diferentes propostas se aproximam e se afastam, especialmente para permitir explicitar possíveis vínculos entre compreensões CTS e os espaços pedagógicos. Além disso, tal entendimento pode contribuir para identificar eventuais limitações e potencialidades, não só no sentido de acompanhar tendências e localizar prioridades de pesquisa, mas, sobretudo, como condição necessária para o encaminhamento de diálogos e novas práticas.

Nesse sentido, o objetivo deste trabalho é investigar uma possibilidade de sistematização das perspectivas presentes nas várias abordagens que se reconhecem como inseridas na pluralidade do movimento CTS, sinalizadas nas propostas desenvolvidas no contexto educacional brasileiro. Como ponto de partida, investigou-se quais elementos e dimensões poderiam caracterizar tal quadro, identificando parâmetros e propósitos mais significativos, para, em seguida, buscar articulações ente ambos. 
Vale ressaltar que com essa identificação e caracterização de abordagens CTS, não se tem a pretensão de oferecer, simplesmente, enquadramentos classificatórios. Ao contrário, e sobretudo, pretendemos uma sistematização de potencialidades e de espaços de atuação, que possam favorecer o diálogo e contribuir para um avanço desse movimento na educação científica.

\section{Encaminhamentos metodológicos}

Uma possibilidade de alcançar essa pretensão, perpassa investigar a construção de uma matriz de referência, constituída por planos de análise de diferentes naturezas, onde possam ser representadas, ou onde seja possível localizar, de forma sistematizada, as diferentes abordagens e iniciativas, permitindo uma compreensão mais abrangente da pluralidade do movimento. Dessa forma, os planos de análise são, também, objetos desta investigação e não passíveis de uma definição a priori.

Diante disso, optou-se por desenvolver um percurso de pesquisa organizado em quatro momentos, que envolveram: (1) analisar a produção recente da área de ensino de ciências no Brasil e (2) estudar referenciais teóricos sobre o assunto, para, com isso, (3) buscar construir um instrumento de referência que dê conta de sistematizar a diversidade de abordagens; e, de posse desse instrumento, (4) voltar para a análise da produção, validando, reformulando e reconsiderando o instrumento construído.

Ou seja, o objetivo do presente trabalho é caracterizar as diferentes abordagens CTS presentes no campo da educação científica brasileira e, para isso, é necessário o desenvolvimento de um instrumento (matriz de referência) capaz de sistematizar os diferentes recortes ou dimensões relevantes. Dessa forma, sendo um problema de duas faces, também o trabalho de investigação deve ser desenvolvido em dois âmbitos complementares, sendo um de base empírica e, o outro, de aproximação teórica.

Do ponto de vista teórico, foram selecionados estudos representativos de discursos sobre ciência, tecnologia, sociedade, educação e educação científica, presentes de forma mais intensa nos trabalhos sobre CTS e/ou que, a nosso ver, poderiam trazer contribuições para o debate. Nesse sentido, os estudos de Popper (1982), Kuhn (1962), Latour e Woolgar (1979), Bourdieu (2004), Leydesdorff e Etzkowitz (2008), Shinn e Ragouet (2008), Lacey (2010), contribuíram para as discussões em torno do processo de construção conceitual e produção social da ciência, bem como para as relações entre ciência e valores. Vargas (1994), Dusek (2009), Oliveira (2003), Pinto (2005), Mitchan (1994), Feenberg (2010), Dagnino (2007, 2008a, 2008b), Baumgarten (2008), Herrera (2003), contribuíram para as discussões em torno da tecnologia, suas definições e relações com a ciência e o desenvolvimento social, esse último, por meio de discussões sobre política científica tecnológica. Japiassu (2005), Morais 
(2007), Beck (2010), Santos B. (2007) e Morin (2005, 2009, 2011), contribuíram para discussões centradas na sociedade, mas relacionadas às implicações da ciência e da tecnologia. Por fim, Freire (1979, 1982, 1987, 2000, 2006), Gadotti (1995), Silva (2010), Freiras e Biccas (2009), Aranha (2003), Saviani (2007), Krasilchik (1987), Megid (1999), Delizoicov (2004) e Salem (2012) contribuíram para as discussões em torno da educação e da educação científica. Certamente esses estudos não esgotam as possibilidades; mas contribuem para uma sistematização de perspectivas.

Paralelamente, do ponto de vista empírico, foi desenvolvido um levantamento de artigos publicados em revistas brasileiras da área de Ensino de Ciências e nos anais dos Encontros Nacionais de Pesquisadores em Educação em Ciências (ENPEC), no período de 2000 a 2010. Nesse universo, foram encontrados mais de 100 trabalhos que fazem menção à CTS no título, resumo ou palavras-chave.

Tanto do ponto de vista teórico como empírico, as etapas dessa investigação foram desenvolvidas de acordo com a metodologia da Análise Textual Discursiva (ATD), que corresponde à análise de dados e informações de natureza qualitativa, desenvolvida com a finalidade de produzir novas compreensões sobre os fenômenos e discursos investigados (MORAES; GALIAZZI, 2007). Assim, a escolha dessa forma de análise é justificada por sua proposta de combinar análise rigorosa e síntese subsequente, possibilitando a reconstrução do texto/discurso de forma a ampliar seus significados, especialmente no que diz respeito aos discursos implícitos. Além disso, a ATD permite um processo de categorização emergente, no qual as categorias são construídas ao longo do processo, ou seja, à medida que a análise for realizada, como pretendido nesta investigação.

A análise desse conjunto de publicações da área de Ensino de Ciências indicou, de partida, a dificuldade em identificar a natureza da abordagem CTS de cada produção, na medida em que nem sempre são explicitados, com clareza, os pressupostos que as fundamentam. Essa ausência de explicitações, na maior parte das vezes, não corresponde a uma lacuna propriamente dita, mas está relacionada à própria natureza dos trabalhos e das práticas propostas. Em função disso, as reflexões teóricas e a análise da produção da área de Ensino de Ciências foram desenvolvidas em trajetórias paralelas, de forma a se alimentar reciprocamente. A articulação entre ambas foi construída no processo, sendo que elementos identificados em um âmbito proviam de indagações a serem aprofundados no outro.

Resultados parciais dessa investigação foram apresentados anteriormente (STRIEDER; KAWAMURA, 2009; 2010; 2011; 2012; 2014), discutindo de forma mais detalhada os procedimentos de análise, a emergência de categorias e o conjunto de sinalizações presentes. Esses aspectos não serão retomados neste artigo, uma vez que se busca apresentar a vinculação das dimensões e enfoques presentes nos trabalhos e nos estudos 
teóricos de referência. Ainda assim, a menção à existência de uma base empírica é importante para expressar a estratégia de construção utilizada.

Nesse sentido, para além de aspectos mais locais, a contribuição central, no presente artigo, é buscar construir um quadro geral, articulado a partir dos vários enfoques identificados, sistematizando-os em suas diferentes dimensões e acrescentando os vínculos mais expressivos.

\section{Identificação de dimensões}

Do conjunto dessas investigações e análises, foi possível perceber que há duas dimensões específicas a serem contempladas, relacionadas: (i) à maneira como as relações CTS são abordadas e (ii) às diferentes perspectivas educacionais envolvidas. Partiu-se da hipótese de que essas são dimensões necessárias e bem caracterizadas, ainda que de naturezas diferentes, com potencial para expressar os vínculos e articulações presentes nas discussões que vêm ocorrendo em diferentes áreas do conhecimento e se cruzam no âmbito da educação CTS. Do ponto de vista dessas articulações, destacam-se a função social da escola, da educação científica, da ciência e da tecnologia; e, além disso, a função em sua relação com modelos de sociedade.

A primeira dimensão é representada pelo que se denominou por Parâmetros da educação CTS, que sintetizam diferentes olhares para a ciência, a tecnologia e a sociedade, e podem servir de aporte para a inserção de discussões pertencentes ao campo CTS na educação científica. A segunda dimensão é representada pelo que denominamos por Propósitos da educação CTS, que sintetizam diferentes perspectivas educacionais e seus significados na educação CTS.

Vale insistir e ressaltar que esses parâmetros e propósitos resultam de um constante ir e vir, da teoria aos dados, alimentado pela busca de articulações entre ambos. Ou seja, resultam do cruzamento das informações oriundas do estudo de referenciais teóricos e de análises da produção brasileira da área de Ensino de Ciências sobre CTS. Contudo, o foco do presente artigo, como já mencionado, não é apresentar uma análise quantitativa ou qualitativa de trabalhos e/ou referenciais teóricos, mas uma reflexão em torno dos parâmetros e propósitos da educação CTS, destacando limites e potencialidades de diferentes abordagens. Para isso, são mencionados alguns referenciais teóricos estudados, com a intenção de explicar e caracterizar os olhares; também, a título de exemplificação, são citados alguns trabalhos analisados $^{2}$. Segue, portanto, a discussão desses parâmetros e propósitos da educação CTS.

\footnotetext{
${ }^{2}$ Um detalhamento desta investigação pode ser encontrado em Strieder (2012).
} 


\section{Parâmetros da educação CTS}

Dos estudos representativos de discursos sobre ciência, tecnologia e sociedade, percebeu-se, com maior ou menor intensidade, a presença de três elementos relacionados a denominações adotadas como: (i) racionalidade científica, (ii) desenvolvimento tecnológico $e$ (iii) participação social, cujos sentidos e características são discutidos na sequência. Cada um deles pretende expressar, internamente, articulações entre aspectos relacionados tanto à ciência e à tecnologia, quanto à sociedade, evitando formas de segmentação dos mesmos; representam assim, princípios ou referências a partir dos quais é possível estabelecer e caracterizar relações entre os três elementos da tríade CTS e entre esses e a educação científica. Para cada parâmetro, foram resgatados e construídos cinco perfis característicos, visando às possibilidades de articulações com os propósitos educacionais que serão apresentados adiante.

\section{(i) Racionalidade científica}

Discussões sobre a racionalidade científica e seu papel na construção da ciência e na sociedade estão presentes nos diferentes discursos sobre a ciência, seja seguindo uma vertente mais empírico-indutivista e/ou positivista num extremo (a exemplo do discurso de Francis Bacon e de membros do Círculo de Viena), seja associando aos valores pessoais/sociais em outro extremo (LACEY, 2010). Ao mesmo tempo, essas discussões perpassam as questões levantadas por Popper (1982), Kuhn (1962), Latour e Woolgar (1979) e Bourdieu (2004). Também, é possível perceber visões de racionalidade científica nos discursos sobre a tecnologia, em especial nos trabalhos de Pinto (2005), Feenberg (2010) e Dagnino (2007, 2008a), ainda que esse não seja o foco dos mesmos. Além desses, em olhares centrados na sociedade, a exemplo dos desenvolvidos por Japiassu (2005), Beck (2010) e Morin (2009), comparece uma discussão sobre o papel da racionalidade científica, em especial, quando analisam sua influência na cultura, na sociedade de risco ou no pensamento (respectivamente). Assim, esse parâmetro, mais do que um olhar sobre a ciência, representa uma maneira de olhar para as relações CTS.

Também, a partir dos estudos investigados, é possível perceber a possibilidade de existência de uma ciência não caracterizada somente por princípios lógicos e empíricos, ainda que racional. É nessa compreensão de racionalidade que se insere a presente discussão, ou seja, no reconhecimento de que há diferentes racionalidades presentes na construção da ciência e que a ciência é racional em sua essência, mas que isso não implica em certezas e em progresso garantido. Outras perspectivas são possíveis e o primeiro passo para o desenvolvimento delas é o reconhecimento das suas limitações. 
Articulando essas discussões aos trabalhos da área de Ensino de Ciências analisados, propõe-se que são possíveis diferentes abordagens sobre racionalidade científica na educação CTS, associados a:

(1R) explicitar a presença da ciência no mundo;

(2R) discutir malefícios e benefícios dos produtos da ciência;

(3R) analisar a condução das investigações científicas;

(4R) questionar as relações entre as investigações científicas e seus produtos;

(5R) abordar as insuficiências da ciência.

A perspectiva $(1 R)$ explicitar a presença da ciência no mundo representa abordagens que enfatizam a importância do conhecimento científico para compreender o mundo natural ou artificial. Nesse caso, o conhecimento científico é apontado como a principal (ou mais completa) possibilidade de compreensão da realidade, ou do tema/assunto em questão. No contexto educacional, essa abordagem de racionalidade está presente em propostas que centram suas discussões nos conhecimentos científicos necessários para compreender determinado tema. Por exemplo, em propostas sobre aquecimento global que estão centradas em conteúdos de Física Térmica ou em propostas sobre organismos geneticamente modificados que estão centradas nas Leis de Mendel. Nesses casos, a intenção relaciona-se à explicitação da presença da ciência na sociedade e, sendo assim, a racionalidade científica em si não é objeto de questionamentos ou críticas. Ao mesmo tempo, a "explicação científica" não é entendida como sinônimo de verdade acerca da realidade ou de observância de um conjunto de regras seguidas por meio de um método seguro e infalível; ela é apenas reconhecida e permite compreender a realidade. Essa abordagem, portanto, pode ser entendida como uma primeira aproximação para a questão e contribui, principalmente, para explicitar aspectos do conhecimento científico no cotidiano dos alunos. Cabe ressaltar que esse olhar, ao extremo, pode levar a uma compreensão de racionalidade entendida como garantia de verdade absoluta, e de ciência como um processo de desocultamento da realidade orientado por regras estabelecidas.

$\mathrm{Na}$ abordagem $(2 R)$ discutir malefícios e benefícios dos produtos da ciência, assim como na anterior, a racionalidade não é alvo de discussões e/ou questionamentos. Nesse caso, o que é passível de reflexão e de questionamento são os usos atribuídos aos produtos dessa racionalidade. $\mathrm{O}$ resultados da ciência são colocados a serviço da sociedade, e esta deve decidir sobre seu uso (para o bem ou para o mal). Diferentemente do anterior (1R), portanto, começam a aparecer algumas críticas relacionadas aos usos sociais da ciência. No contexto da educação CTS, esta perspectiva está associada, por exemplo, à discussão de argumentos contra ou a favor do uso dos motores à combustão interna, da energia nuclear, etc. Vale ressaltar que Auler (2011) questiona essa visão preocupada em analisar os impactos, pós- 
produção, da CT na sociedade. De acordo com ele, avaliações desse tipo mantêm intocável o cerne da questão, que deveria ser a crítica aos processos e não aos produtos e às pessoas, envolvendo uma análise a priori e não a posteriori. Contudo, a nosso ver, é importante reconhecer que essa abordagem contribui para o levantamento de alguns questionamentos relacionados à ciência, ainda que os mesmos não foquem o cerne da questão ou não estejam relacionados à racionalidade propriamente dita. Também, é importante reconhecer que, no âmbito das práticas escolares, principalmente das implementações em sala de aula, muitas vezes, representa a estratégia crítica possível de ser abordada diante de uma dada situação, com contribuições à formação cidadã.

$\mathrm{Na}$ abordagem (3R) analisar a condução das investigações científicas, a racionalidade da ciência entendida como garantia de verdade absoluta e universal, passa a ser questionada na medida em que não condiz com o processo real de construção das ciências. A condução das investigações científicas envolve, também, fatores humanos e sociais; a ciência é uma construção humana e, nesse sentido, sua construção tem relações profundas com o contexto social. Há uma crítica à concepção de que a ciência é neutra porque procede de acordo com o método científico, segundo o qual a escolha racional entre as teorias não deve envolver, e de maneira geral não tem envolvido, elementos sociais. Nesse caso, ainda não se trata de discutir o valor intrínseco da ciência (que comparece com o mesmo status de conhecimento do grupo anterior), mas de questioná-la como detentora de verdades absolutas. As verdades são construções históricas e provisórias, a serem revistas em função dos contextos sociais. Essa abordagem, portanto, está associada às discussões mais voltadas à natureza da ciência, a exemplo do que Santos (2001) denomina CTS com ênfase em C. Também, essa visão prevalece em muitas propostas CTS voltadas ao estudo da história e natureza da ciência.

$\mathrm{Na}$ abordagem (4R) questionar as relações entre as investigações científicas e seus produtos, a racionalidade científica é questionada por responder a demandas de grupos sociais específicos. A crítica recai nos rumos das pesquisas, nas razões para pesquisar um determinado problema e não outro; na fragmentação da produção, que não permite o domínio sobre o que está sendo pesquisado. Assim, a própria produção da ciência (incluindo as escolhas de temas e metodologias de pesquisa), mais do que sofrer influências é ditada pelos interesses econômicos, políticos e sociais do poder dominante; e, portanto, não responde apenas ao interesse em desenvolver o conhecimento como um fim em si mesmo. Associado a isso, começam a aparecer, de maneira mais explícita, as relações com a tecnologia e com o desenvolvimento social. A nosso ver, essa era a crítica principal dos estudos que deram origem às discussões CTS na década de 1960. No contexto educacional, a mesma se faz presente, por exemplo, em propostas e ações que questionam os rumos atuais de determinadas pesquisas; quais pesquisas, eventualmente, deixam de ser desenvolvidas ou são menos 
incentivadas, em função de outras; abordam questões sobre quem, de que forma, com que financiamento, sob que responsabilidade, etc. desenvolve, gerencia e atua nesse âmbito.

$\mathrm{Na}$ abordagem $(5 R)$ abordar as insuficiências da ciência, o conhecimento científico é visto como insuficiente para compreender e resolver problemas da realidade, em função da complexidade do mundo real. Dessa forma, reconhece-se que existe uma racionalidade científica, um conhecimento que atende a certas características que lhe dão um valor diferenciado frente aos outros conhecimentos. No entanto, esse conhecimento não tem potencial para fornecer, sozinho, uma compreensão da complexidade do mundo contemporâneo, porque não é completo. Ainda que seja rigoroso e independente de sua forma de construção, não dá conta de um conhecimento definitivo e inquestionável de sistemas complexos como os reais. Além disso, ou por isso, a racionalidade científica não tem condição de assegurar o progresso, sendo apenas uma das ferramentas nas decisões de valor sobre o que seja progresso. Assim, o conhecimento científico é insuficiente para assegurar decisões sociais mais amplas, que necessariamente envolvem outros valores. É possível perceber essa preocupação em revisões teóricas sobre o movimento CTS, quando discutem a necessidade de se buscar novos direcionamentos para a política científica e tecnológica brasileira, o que perpassa por superar a ideia de que as conclusões científicas são inquestionáveis e que mais ciência e tecnologia (CT), necessariamente, conduzirão ao bemestar social.

(ii) Desenvolvimento tecnológico

Discussões sobre o desenvolvimento tecnológico estão presente em vários estudos relacionados à ciência, à tecnologia e ao desenvolvimento social, sob diferentes pontos de vista. Nesse sentido, destacam-se, por exemplo, as críticas aos discursos salvacionistas, que defendem que mais tecnologia resultará, inevitavelmente, em mais bem-estar social (WINNER, 1987; PINTO, 2005). Também, recebem destaque as discussões sobre as especificidades do conhecimento tecnológico, a exemplo das que comparecem em Vargas (1994), Pinto (2005) e Dusek (2009), que buscam esclarecer os vários significados atribuídos à tecnologia, relacionados ao estudo da técnica, à ciência, à artefato, à instrumento, à organização de ações, a um sistema de relações, a um sistema sociotécnico, etc. Além disso, há reflexões que enfatizam que a questão central não é a tecnologia em si, mas as perspectivas de desenvolvimento que a orientam, ou seja, a variedade de tecnologias e caminhos de desenvolvimento entre os quais deve-se escolher, a exemplo das realizadas em Herrera (2003), Feenberg (2010) e Lacey (2010). Nesse contexto, encontram-se as análises e críticas do modelo de política científica e tecnológica adotado por países subdesenvolvidos, como o Brasil e outros da América Latina, a exemplo das realizadas em Dagnino (2007, 2008a, 2008b) e Baumgarten (2008). 
Particularmente no que se refere à questão do desenvolvimento, vale ressaltar a proposta de Dagnino (2003), que reconhece quatro perspectivas distintas. A primeira, entende que o desenvolvimento em CT gera o desenvolvimento social. A segunda, com base em ideais marxistas, entende que CT são influenciadas por interesses de classes e, dessa forma, jamais poderão trazer o bem-estar social de toda a população. A terceira, defende a necessidade de tecnologias alternativas, por exemplo, que não prejudiquem o meio ambiente, sem questionar as estruturas de poder dominantes. A quarta e última, defende que os países latino-americanos deveriam internalizar uma política própria de produção de tecnologias, coerente com as suas necessidades.

Articulando essas discussões aos trabalhos analisados, da área de Ensino de Ciências, entende-se que diferentes abordagens sobre desenvolvimento tecnológico são possíveis na educação CTS, as quais estão centradas em:

(1D) abordar questões técnicas;

(2D) analisar organizações e relações entre aparato e sociedade;

(3D) discutir especificidades e transformações acarretadas pelo conhecimento tecnológico;

(4D) questionar os propósitos que tem guiado a produção de novas tecnologias;

(5D) discutir a necessidade de adequações sociais.

Na perspectiva (1D) abordar questões técnicas, há um reconhecimento da tecnologia, mas não está associado a uma discussão sobre o desenvolvimento científico-tecnológico e sim a uma compreensão de questões técnicas, a exemplo das partes ou dos equipamentos que compõem um determinado aparato e que são necessários para o seu funcionamento. $\mathrm{O}$ desenvolvimento tecnológico não é foco de atenção; ele não influencia nem é influenciado pela sociedade; não é avaliado nem como positivo, nem como negativo. Nessa abordagem, a tecnologia é encarada como uma ferramenta ou instrumento com que a espécie humana satisfaz suas necessidades; não há uma preocupação com os sentidos e significados desse termo ou com as relações que estabelecem com a ciência. Em extremos pode levar à compreensão do processo de produção da tecnologia como algo fechado e neutro, independente da sociedade. Na esfera educacional associa-se, por exemplo, à construção de uma maquete em que se mostram o funcionamento e as partes de determinado aparato; pode envolver, também, uma discussão sobre como usar determinado aparato da maneira mais correta, eficaz e/ou sustentável. De acordo com Santos e Mortimer (2002), na educação CTS, deve-se ir além da explicação técnica do funcionamento de artefatos, pois essa perspectiva não está associada, somente, a ensinar a usar ou a absorver ferramentas. Contudo, como destacam os próprios autores, esses conhecimentos são importantes no processo de construção de uma sociedade mais democrática e, dessa forma, devem estar presentes na educação CTS. 
$\mathrm{Na}$ abordagem (2D) analisar organizações e relações entre aparato e sociedade, comparecem discussões sobre o desenvolvimento tecnológico propriamente dito, ainda que de uma forma simples. A ênfase está em discutir as relações sociais tomando por base o produto final, ou seja, o aparato em funcionamento. Reconhece-se que para o funcionamento de determinado aparato são necessários recursos humanos (técnicos, cientistas, etc.) e materiais; também, que há produção de dejetos e resíduos; enfim, que há relações entre aparato e sociedade, as quais podem ser positivas ou negativas. São reconhecidas como positivas, no sentido em que acarretam em desenvolvimento e bem-estar e, como negativas, principalmente, quando há implicações ambientais, como a poluição. Em extremos, quando enfatizados os resultados positivos, tal abordagem pode levar a uma concepção de desenvolvimento linear e mecanicista, na qual a industrialização é entendida como motor do progresso social. Diferente do caso anterior (1D), o aparato passa a estar inserido num contexto e se relaciona com ele, mas essa relação não é passível de críticas, apenas de reconhecimento. Na esfera educacional, por exemplo, comparece em discussões sobre usinas nucleares relacionadas a quem e quantos são os funcionários de uma usina, de onde vem a matéria prima que é utilizada, para onde vão os dejetos, quais os índices de contaminação permitidos, acidentes, etc. Enfim, em propostas em que há uma preocupação com aspectos organizacionais atrelados a determinado aparato.

$\mathrm{Na}$ abordagem (3D) discutir especificidades e transformações acarretadas pelo desenvolvimento tecnológico, os interesses recaem para discussões sobre as especificidades do conhecimento tecnológico, o que envolve uma preocupação com o sentido da palavra tecnologia; levam em conta a diferenciação conceitual e a arqueologia de termos como ciência, técnica e tecnologia. A partir disso é enfatizado que a tecnologia não decorre de forma imediata da ciência, que ela sofre influências da sociedade e difere da técnica. Isso se associa a discussões sobre as diversas relações de produção da tecnologia, que, enquanto organização de ações, envolve diferentes atores sociais; sendo os aparatos compreendidos como resultados dessas relações. Diferente dos casos anteriores, aqui se passa a olhar para o processo de concepção/produção e não somente para o produto final, ainda que não entrando em discussões mais críticas a respeito dos propósitos que tem guiado determinadas ações. $\mathrm{Na}$ esfera educacional, um exemplo seria analisar o processo de construção e funcionamento de uma usina, com ênfase nas mudanças acarretadas na região devido à sua implantação; também, a análise dos diferentes modelos de usina, antigos e atuais, suas semelhanças, diferenças e implicações.

Na perspectiva (4D) questionar os propósitos que tem guiado a produção de novas tecnologias, a ênfase recai no reconhecimento de propósitos do desenvolvimento. Há um abandono da ideia de que o modelo de desenvolvimento seguido nos últimos séculos é o 
melhor possível e de que ele é resultado direto do conhecimento científico e tecnológico. A tecnologia é vista enquanto sistema que afeta a vida em sociedade, que modela valores, motivações, relações sociais e interpessoais. Há uma rejeição à noção de tecnologia neutra e uma defesa à ideia de que a tecnologia é uma estrutura cultural que encarna valores de um grupo social específico. Para elucidar essa afirmação, é enfatizado que o progresso tecnológico não tem atendido às necessidades básicas da população como um todo, mas tem servido para a promoção de interesses de determinados grupos. Essa questão tem sido bastante enfatizada na educação CTS em discussões de natureza teórica, quando os autores defendem a necessidade de perceber, também, o que está implícito; o que está por trás das forças políticas e sociais que orientam o desenvolvimento.

A perspectiva $(5 D)$ discutir a necessidade de adequações sociais, entende que a tecnologia deve ser pensada em contexto, pois não é qualquer tecnologia/inovação que irá resultar em desenvolvimento e bem-estar social. Esse não é entendido como um subproduto direto do crescimento econômico, que, por sua vez, resulta do desenvolvimento tecnológico. O desenvolvimento da tecnologia se origina em um grupo particular, com condições culturais e socioeconômicas definidas e pode não se adequar em ambientes diferentes. Há uma defesa em prol de sistemas que desenvolvam tecnologias baseadas em elementos culturais das sociedades, que busquem satisfazer as necessidades básicas de uma determinada população. A ideia é minimizar os riscos sem abdicar dos benefícios, enfatizando um sistema tecnológico capaz de se adequar a uma sociedade democrática, com características humanas e regionais. Essa abordagem tem estado presente em alguns artigos teóricos da área de Ensino de Ciências, fundamentados no PLACTS.

\section{(iii) Participação social}

A participação social também recebe destaque nos estudos analisados, ainda que sob diferentes fundamentações. Por exemplo, Lacey (2010), ao discutir a importância dos valores na construção da ciência, chama atenção para o desenvolvimento das políticas públicas, que deveriam ser determinadas por comissões formadas por cientistas e, também, por grupos que representam diferentes perspectivas de valores da sociedade como um todo. Beck (2010), ao analisar a sociedade de risco, argumenta que são necessárias mais esferas políticas participando das decisões sobre CT, em especial porque os problemas atuais envolvem riscos e incertezas e não serão resolvidos unicamente pelo viés científico. Japiassu (2005) critica o olhar ingênuo que a população tem com relação à ciência, entendendo-a como absoluta, infalível, condutora inexorável ao progresso, à sabedoria e à felicidade e defende que a superação dessa alienação será possível se houver uma maior participação por parte da sociedade em questões envolvendo CT. Em Morin (2011), a preocupação com a participação social está associada à importância de confederações que busquem responder às necessidades 
vitais planetárias; para o autor, é preciso que o pensamento da sociedade abandone o paradigma simplificador e venha a se inserir em um paradigma da complexidade. Por fim, também nos trabalhos de Herrera (2003) e Feenberg (2010), voltados à análise das políticas de CT, há um destaque para a necessidade de uma participação da sociedade nos rumos dessas políticas, em especial quando defendem que o desenvolvimento tecnológico deve ser pensado e adequado à sociedade.

Vale esclarecer que a participação social pode assumir diferentes graus, que dependem dos papéis atribuídos aos dirigentes e subordinados e pode variar de acordo com a natureza da decisão a ser tomada, como aponta Bordenave (1994). Diante dessa diversidade de compreensões e possibilidades, o termo participação social, é utilizado na presente discussão com a intenção de sinalizar diferentes envolvimentos com as questões CTS.

Seguindo essas considerações, e a partir da análise dos trabalhos da área de Ensino de Ciências, entende-se que diferentes abordagens de participação social são possíveis na educação CTS, associados a:

(1P) adquirir informações e reconhecer o tema e suas relações com a ciência e a tecnologia;

(2P) avaliar pontos positivos e negativos associados ao tema, envolvendo decisões individuais e situações específicas;

(3P) discutir problemas, impactos e transformações sociais da ciência e da tecnologia envolvendo decisões coletivas;

(4P) identificar contradições e estabelecer mecanismos de pressão;

(5P) compreender políticas públicas e participar no âmbito das esferas políticas.

A perspectiva (1P) aquisição de informações e reconhecimento do tema e suas relações com a ciência e a tecnologia está associada a uma aproximação maior da sociedade para com a ciência e a tecnologia, que passa a estar informada sobre os avanços e problemas mais recentes, ainda que sem avaliar riscos e benefícios ou discutir implicações e transformações sociais. Nas propostas de práticas educacionais, essa ênfase associa-se à discussão de temas que estão em pauta na mídia ou no dia-a-dia dos alunos, com a intenção de contribuir para que os alunos os reconheçam e compreendam como esses se articulam ou se associam à ciência e à tecnologia. Nesse caso, não há uma preocupação explícita com a participação social propriamente dita, mas há uma expectativa de envolvimento social com temas relacionados à ciência e à tecnologia. Vale lembrar que a participação pautada unicamente no campo científico-tecnológico tem sido questionada no âmbito do movimento CTS e, como enfatizado por Auler (2011), representa um retorno à tecnocracia. Apesar dessas críticas, considerar a participação, ainda que sob o ponto de vista do reconhecimento do tema e suas relações com a ciência e a tecnologia, é importante para a formação de cidadãos, visto 
que pode contribuir para a construção de uma nova imagem do conhecimento científico escolar. Também, discussões dessa natureza podem representar um ponto de partida para as abordagens CTS.

Na perspectiva (2P) avaliação de pontos positivos e negativos associados ao tema, envolvendo decisões individuais e situações específicas, a participação da sociedade se dá no âmbito da avaliação de pontos positivos e negativos associados ao uso de determinado resultado/produto da CT, o que pode resultar em uma mudança de atitudes de cunho individual. Ou seja, está orientada para reivindicações específicas, que possuem um fim em si e implicam em decisões individuais, que ocorrem depois do produto pronto. No cenário educacional, está presente, por exemplo, em propostas que discutem os prós e contras do uso de transgênicos, do celular ou de determinados recursos naturais, como a água. Espera-se, com discussões dessa natureza, contribuir para que o aluno tenha condições de se posicionar a favor ou contra determinado produto da CT e, a partir disso, agir de acordo com seu posicionamento. Em um extremo, propostas balizadas unicamente por essa preocupação, centram-se na apresentação de argumentos favoráveis e contrários do ponto de vista social e econômico e acabam deixando de lado discussões de cunho científico ou tecnológico.

Na perspectiva (3P) discussão de problemas, impactos e transformações sociais da ciência e tecnologia, envolvendo decisões coletivas, a participação perpassa o reconhecimento das transformações sociais causadas pelo desenvolvimento científico-tecnológico, o que deve ocorrer no plano social mais amplo, envolvendo a análise histórica e decisões ou ações coletivas. Diferente da anterior (2P), nesta o foco não é entender aspectos positivos e negativos, mas as implicações em diferentes contextos. Contudo, nesse caso, a participação ainda está relacionada à avaliação dos impactos pós-produção e não ao processo produção em si. No ambiente educacional, comparece, por exemplo, em propostas que analisam as transformações pelas quais a sociedade tem passado em virtude do uso do celular, do computador ou de organismos geneticamente modificados. Também, percebe-se essa abordagem em propostas que estão centradas em congressos de consenso e/ou role play games, que envolvem diferentes atores sociais e permitem análises ou reflexões sobre as consequências de determinadas decisões, tomadas por coletivos.

A perspectiva (4P) identificação de contradições e estabelecimento de mecanismos de pressão perpassa o reconhecimento dos propósitos políticos que levaram ao desenvolvimento de determinado produto da CT, a exemplo da exclusão social e/ou da luta de classes; o que implica em um controle social mais amplo. Diferente das anteriores, aqui reconhece-se uma possibilidade de intervir no processo de produção e/ou implementação de determinado produto da CT. Na educação científica, essa perspectiva comparece, muitas vezes, em propostas e práticas centradas em discussões sobre a implementação de fábricas com ênfase 
na compreensão das relações de poder presentes e as contradições envolvidas. Nesse caso, por exemplo, participar da decisão de implementação de uma fábrica, mais do que discutir riscos e benefícios e compreender as transformações sociais que trará, envolve entender as relações de poder presentes. Ao identificar essas relações e suas contradições podem ocorrer mecanismos de pressão que, neste caso, representam a participação social.

A abordagem (5P) compreensão das políticas públicas e participação no âmbito das esferas políticas, indica que a participação social se dá na esfera das políticas públicas, na definição de seus objetivos, meios para alcançá-los e maneiras de controlar sua implementação. Envolve, portanto, a análise e discussão do contexto em que serão inseridos os novos conhecimentos e/ou produtos da ciência e da tecnologia e, associado a isso, a interação e negociação entre especialistas e população em geral. Há uma defesa pela ação coletiva; pela inclusão, nas agendas de pesquisa, de interesses e questões que dizem respeito a diversos grupos sociais, direta e indiretamente afetados pelos produtos da CT. Na esfera educacional, associa-se, por exemplo, à abordagem de temas controversos e/ou problemas ainda não estabelecidos, a exemplo da transposição do rio São Francisco ou do projeto de instalação de usinas nucleares no nordeste brasileiro, nas quais são enfatizadas questões atreladas às esferas políticas.

Neste tópico, portanto, foram apresentados os parâmetros da educação CTS e suas diferentes perspectivas de compreensão ou abordagens. Ressalta-se que esses devem ser compreendidos como elementos que caracterizam discussões CTS, a partir dos quais é possível articular os três elementos da tríade entre si e à educação científica. No entanto, nas propostas educacionais, o que orienta e dá sentido às abordagens sobre racionalidade científica, desenvolvimento tecnológico e participação social, são propósitos educacionais distintos, os quais serão discutidos na sequência deste trabalho. Esses propósitos não se relacionam diretamente a cada um dos perfis caracterizados, mas, de certa forma, podem ser compreendidos como formas plurais de articulação de suas intenções em níveis mais abrangentes, segundo suas finalidades últimas.

\section{Propósitos da educação CTS}

A partir do estudo dos autores mencionados, articulado a análise de trabalhos sobre CTS no ensino de Ciências, foi possível concluir que diferentes propósitos educacionais têm guiado a educação CTS, os quais podem ser agrupados em três grandes grupos que buscam uma educação científica que contribua para o desenvolvimento de: (i) percepções entre o conhecimento científico escolar e o contexto do aluno; (ii) questionamentos sobre situações sociais relacionadas à cidadania e (iii) compromissos sociais diante de problemas ainda não estabelecidos. 
Esses propósitos, mesmo diferentes, podem ser entendidos como complementares em termos de formação científica. Todos desempenham, portanto, um papel importante na busca por mudanças no processo de ensino-aprendizagem de Ciências, contemplando diferentes aspectos. Ainda que possa parecer existir uma hierarquia implícita nessa forma de identificação e apresentação das perspectivas educacionais, não é essa a finalidade. Diferentes propósitos correspondem a diferentes situações, ambientes escolares e possibilidades de atuação, ou mesmo a momentos sucessivos de apropriação de intenções, como é descrito a seguir.

\section{(i) Desenvolvimento de percepções}

A busca pelo desenvolvimento de relações e/ou percepções entre o conhecimento científico escolar e o contexto do aluno tem sido alvo de preocupação a longa data. Associado à superação da falta de motivação e da baixa aprendizagem dos alunos em Ciências, essa preocupação passou a estar no rol das discussões sobre a melhoria do ensino, principalmente, das últimas décadas do século XX.

Essa preocupação implica na busca por elementos que contribuam para a ilustração, aplicação e exemplificação do conhecimento científico escolar. Relaciona-se à construção de uma nova imagem do conhecimento científico escolar, dando ênfase tanto para questões presentes no dia-a-dia, quanto para questões científicas e/ou tecnológicas. Nesse sentido, contextualização é entendida como meio facilitador para a compreensão e construção de conceitos ou como estratégia para dar significado ao conhecimento, seja por despertar o interesse dos alunos ou por ilustrar os conceitos trabalhados.

As preocupações voltam-se à forma de facilitar o entendimento dos conteúdos curriculares, sobretudo através de exemplos, sem necessariamente questionar a seleção e o papel dos conteúdos curriculares já estabelecidos. De certa forma, parte-se do pressuposto de que o conhecimento escolar é algo dado, cabe encontrar maneiras de abordá-lo e permitir ao aluno perceber seu significado. Exemplos, como do funcionamento de aparatos ou de situações que indicam a presença da ciência na sociedade, são pensadas com a intenção de facilitar o processo de ensino-aprendizagem, ou seja, a apreensão e compreensão de conhecimentos científicos por parte dos alunos.

Especificamente no que se refere às discussões CTS, nesse caso, os aspectos mais amplos relacionados à ciência, à tecnologia e/ou à sociedade contribuem para contextualizar o conhecimento científico a ser trabalhado, buscando uma aproximação com a vivência cotidiana do aluno. Nesse caso, por exemplo, pode haver ênfase em um ou mais dos seguintes aspectos relacionados à racionalidade científica, desenvolvimento tecnológico e participação social: explicitação e/ou reconhecimento da presença da ciência e/ou da tecnologia no mundo e compreensão de questões técnicas, como o funcionamento de aparatos tecnológicos. 
Em casos menos críticos, assumir esse propósito pode levar a um caminho contrário ao defendido pelo campo CTS em sua origem. Por exemplo, enfatizar a importância do conhecimento científico para compreender o mundo natural ou artificial, pode levar a uma compreensão de ciência entendida como garantia de verdade absoluta. Também, discutir somente o funcionamento de aparatos pode levar à compreensão de que a tecnologia é simplesmente uma ferramenta com que a sociedade satisfaz as suas necessidades, isenta de juízos de valor.

Particularmente no que se refere a exemplares de práticas em acordo com esse propósito, pode ser incluída, por exemplo, a proposta de Angotti et al. (2001), centrada na abordagem e compreensão dos princípios físicos relacionados ao funcionamento de aparatos presentes no cotidiano, como a bicicleta e o ventilador. Também, e ainda como exemplo, a proposta desenvolvida por Tavares e Soares (2005), centrada no estudo do trânsito, mais especificamente, na compreensão do movimento de veículos a partir de conhecimento da Cinemática. Por fim, o trabalho desenvolvido por Bernardo et al. (2005) apresenta aproximações com este propósito, no sentido em que há uma preocupação em estabelecer relações entre o conceito de potência e equipamentos presentes no cotidiano dos alunos, a exemplo de eletrodomésticos e motores de automóveis.

\section{(ii) Desenvolvimento de Questionamentos}

O discurso da formação do cidadão crítico, consciente e participativo, passou a ser incorporado, de forma mais efetiva, pelo ensino de Ciências, a partir de meados da década de 1980 (DELIZOICOV; ANGOTTI, 1990). As novas propostas educativas, desenvolvidas a partir dessa década, enfatizavam a necessidade de levar os estudantes a desenvolverem o pensamento reflexivo e crítico; a questionarem as relações existentes entre a ciência, a tecnologia, a sociedade e o meio ambiente e a se apropriarem de conhecimentos relevantes científica, social e culturalmente. O desenvolvimento de questionamentos apresenta aproximações com esse universo de preocupações.

Esse propósito envolve, portanto, a defesa pela compreensão de questões sociais relacionadas à cidadania, mesmo que não controversas, mas partilhadas largamente e consideradas como problemáticas na sociedade atual. Mais do que contextualizar o conhecimento científico escolar, busca discutir as implicações do desenvolvimento científicotecnológico na sociedade e, com isso, almeja uma compreensão sobre a utilização responsável dos recursos naturais e aparatos tecnológicos. Também, de acordo com esse propósito o conhecimento científico deixa de ser a finalidade do processo de ensino-aprendizagem e passa a ser entendido como meio para a formação de cidadãos aptos a julgar e tomar decisões conscientes. 
Associado a isso, se fazem presentes questionamentos sobre a seleção e organização dos conteúdos escolares. Também, é possível perceber aproximações com as teorias críticas e pós críticas do currículo (SILVA, 2010), que surgiram nas décadas de 1960 e 1980, respectivamente, em meio a movimentos sociais e culturais. As mesmas argumentam que nenhuma teoria é neutra e desinteressada, mas que está, inevitavelmente, implicada em relações de poder, sejam elas relacionadas às lutas de classe ou às questões de gênero, etnia, raça e sexualidade (pós críticas).

Em síntese, como destaca Silva (2010), essas teorias surgiram para repensar o papel do currículo, que se dizia neutro na teoria tradicional. A partir dessas ideias, o currículo passou a ser entendido como um espaço de poder, um meio pelo qual é reproduzida e mantida uma ideologia dominante, podendo também ser um espaço de construção, de libertação e de autonomia. É nesse contexto, que o desenvolvimento de posicionamentos questionadores (assim como o desenvolvimento de compromissos sociais) se aproxima, principalmente, dos pressupostos das teorias críticas do currículo.

Essa perspectiva educacional aproxima-se, também, do que defendem os Parâmetros Curriculares Nacionais (PCN), em especial no que se refere à promoção de competências e habilidades que sirvam para o exercício da cidadania. De acordo com os PCN isso implica em, por exemplo, entender equipamentos e procedimentos técnicos, obter e analisar informações, avaliar riscos e benefícios presentes em processos tecnológicos (BRASIL, 1998). Nesses parâmetros, ciência e suas tecnologias devem ser abordadas considerando o processo histórico, social e cultural e o reconhecimento e discussão de aspectos práticos e éticos da ciência no mundo contemporâneo. A partir disso, os documentos destacam a importância de tomar como ponto de partida do processo de ensino-aprendizagem elementos do domínio vivencial dos educandos, da escola e de sua comunidade, pois isso permitirá que os alunos percebam o significado do aprendizado (BRASIL, 1998).

No caso deste propósito, o foco passa a ser, não mais o conhecimento científico em si mesmo, mas a compreensão de situações/problemas que fazem parte do cotidiano do aluno. A partir das quais são desenvolvidos questionamentos e posicionamentos em torno do conhecimento e da realidade.

No que se refere aos parâmetros da educação CTS, o desenvolvimento de questionamentos implica, por exemplo, discutir benefícios e malefícios dos produtos da ciência; analisar a condução das investigações científicas; questionar as relações entre as investigações científicas e seus produtos; analisar as relações aparato - sociedade; discutir especificidades e transformações acarretadas pelo conhecimento tecnológico; questionar os propósitos que têm guiado as produções de novas tecnologias. Associado a isso, pode ter como intenção a busca pela participação da sociedade, seja do ponto de vista das tomadas de 
decisão individuais (discutindo riscos e benefícios) e/ou coletivas (discutindo impactos ou transformações sociais) ou a partir de mecanismos de pressão, identificando contradições presentes, principalmente, no momento de produção da CT.

No trabalho de Souza e Alencar (2007), por exemplo, é possível perceber aproximações com esse propósito, em especial porque há uma ênfase na discussão de argumentos contra ou a favor ao uso dos motores à combustão interna. Também no trabalho analisado por Gouvêa e Leal (2001) e desenvolvido em um museu de ciências, é possível perceber a presença deste propósito, em especial quando há uma ênfase em aspectos relacionados à construção histórica da ciência do ponto de vista dos antecedentes sociais. Em outros trabalhos voltados ao estudo da História da Ciência e Natureza da Ciência, a exemplo do desenvolvido por Vanucchi (1996), também prevalece este propósito. Por fim, inserem-se nesse grupo discussões presentes nos trabalhos de Angotti e Auth (2001) e de Pinheiro et al., (2007), em especial quando é enfatizada a distribuição desigual da ciência e da tecnologia e sua contribuição para a manutenção (dominação) de determinadas minorias sociais.

\section{(iii) Desenvolvimento de Compromissos Sociais}

Uma educação científica que busca compromissos sociais relaciona-se ao desenvolvimento de competências para que a sociedade possa lidar com problemas de diferentes naturezas, tendo condições de fazer uma leitura crítica da realidade que, atualmente, está marcada por desequilíbrios sociais, políticos, éticos, culturais e ambientais. Assim, mais do que contextualizar o conhecimento, compreender o mundo, questioná-lo e/ou se posicionar, de acordo com esse propósito, o que guia a educação é a busca por uma transformação de mundo; a busca por encaminhamentos para problemas reais, que afligem a sociedade com a qual a escola se encontra. Envolve, portanto, ações concretas de intervenção na realidade.

Essa perspectiva apresenta elementos comuns aos pressupostos freireanos, no sentido em que visa abordar a realidade de forma a identificar caminhos para sua transformação. Busca uma relação diferente entre o conhecimento e a sociedade e, coerente com isso, questiona o currículo atual e a função social da escola.

Questionamentos em torno da função social da escola não são novos e recebem destaque e críticas, no Brasil, desde meados do século XX. Nesse universo de discussões, e principalmente de críticas, destaca-se a função da escola enquanto promotora do progresso econômico do país, implantada na década 1950 e 1960 no Brasil. Como colocam Freitas e Biccas (2009), em meados do século XX foi plantada uma ilusão de que para o Brasil se tornar um país desenvolvido (industrializado) era preciso educação. A partir disso, a educação passou a ter uma finalidade econômica, o que se tornou um discurso repetido incansavelmente. Isso fez com as classes menos favorecidas passassem a valorizar a educação 
e a almejar as escolas - "Escolarizar os filhos, ainda que em condições precárias, tornou-se expectativa de quebrar desvantagens econômicas, de cor, de sexo e de origem" (FREITAS; BICCAS, 2009, p. 28). Essa perspectiva, para Freitas e Biccas, desvirtua a função da escola, pois está baseada em uma falsa ideia de democracia - associada ao acesso e não à qualidade da educação oferecida.

Por outro lado, nessas décadas, surgem diversos movimentos de educação popular, que buscam alternativas a esse modelo de escola. Questionam o elitismo do ensino vigente, seus métodos e princípios pedagógicos, que não correspondem ao desenvolvimento do país e à construção da democracia. Dentre esses movimentos destaca-se o coordenado por Paulo Freire, que almejava coincidir a perspectiva de desenvolvimento com um projeto autônomo da nação brasileira. Enfatizava a importância de uma educação que fosse condizente com a realidade brasileira da época, formando homens com consciência dos problemas nacionais e da necessidade de sua efetiva integração no país (FREIRE, 1982). É nesse contexto, também, que o presente propósito da educação científica se aproxima dos pressupostos freireanos.

Nessa concepção, portanto, a função da escola vai além de adequar os jovens para uma vida social e produtiva bem estabelecida; passa a ser capacitar os jovens (de diferentes níveis e classes sociais) para o enfrentamento de novos problemas e para a definição de novos rumos e horizontes para si e para a sociedade com a qual se encontram.

Dessa forma, uma educação CTS em consonância com essa perspectiva implica, por exemplo, discutir as limitações do conhecimento científico para compreender e resolver os problemas sociais; enfatizar a importância de a sociedade almejar outro modelo de desenvolvimento, que busque satisfazer as necessidades básicas de uma determinada população e não gerar lucro econômico; e, buscar uma cultura de participação no âmbito das políticas públicas, na definição de objetivos, meios para alcançá-los e maneiras de controlar sua implementação.

É possível perceber elementos deste propósito em algumas práticas de sala de aula, como a discutida em Amorin (2001); em especial, quando o autor enfatiza que para compreender o "corpo humano" (tema em questão) não basta estudá-lo do ponto de vista da ciência (biologia), é necessário ampliar essa análise incluindo o contexto social (as representações culturais do corpo, a relação homem/máquina).

Certamente essa perspectiva não implica somente em uma mudança de metodologias de ensino, ainda que perpasse por ela. A ela está relacionada, acima de tudo, uma mudança no que se entende por conhecimento escolar e, principalmente, na função social da escola. Contudo, ainda assim, seu desenvolvimento no contexto escolar atual não deixa de ser possível, visto que pode acontecer, por exemplo, a partir de intervenções pontuais sucessivas, com graus de complexidade variados e complementares. 


\section{O universo das possibilidades: uma matriz para situar abordagens CTS}

Como apresentado, os propósitos educacionais (ou seus objetivos formativos últimos) podem priorizar diferentes aspectos, enfatizando percepções, questionamentos ou buscando diferentes formas de compromissos sociais. Não se trata de valorizar mais uma ou outra dentre essas possiblidades, já que as opções de ação educativa incluem múltiplos e variados elementos, em diferentes contextos e espaços.

No entanto, em cada uma dessas opções é possível identificar a predominância de um ou mais parâmetros referentes à racionalidade científica, desenvolvimento tecnológico ou participação social. Não se trata de reconhecer vínculos determinantes, mas afinidades de sentidos e abordagens. Ou seja, parece haver formas de articulação entre propósitos educacionais e parâmetros CTS que se mostram mais diretas e com maior organicidade. Assim, para cada propósito, podem ser apontados diferentes perfis ou abordagens, mais explicitamente, coerentes com ele. Da mesma forma, para cada uma das abordagens associadas aos parâmetros, podem ser sinalizados os propósitos mais diretamente a ela relacionadas.

A Figura 1 retrata a articulação entre os parâmetros e propósitos da educação CTS, discutidos nesse artigo. Ela deve ser entendida como o universo de possibilidades de ações e suas múltiplas ênfases. De certa forma, em uma atividade e prática concreta, muitos desses elementos e aspectos se sobrepõem e, até mesmo, se confundem. Mas a proposta de uma matriz CTS dessa natureza, mais abrangente, parece trazer a possibilidade de explicitação dos vários elementos presentes, de seus limites e possibilidades, contribuindo para escolhas e encaminhamentos. A Figura 1 representa, portanto, elementos que permitem situar e caracterizar diferentes abordagens de educação CTS presentes no contexto educacional brasileiro, explicitando as relações estabelecidas entre parâmetros e propósitos desse movimento educacional. 


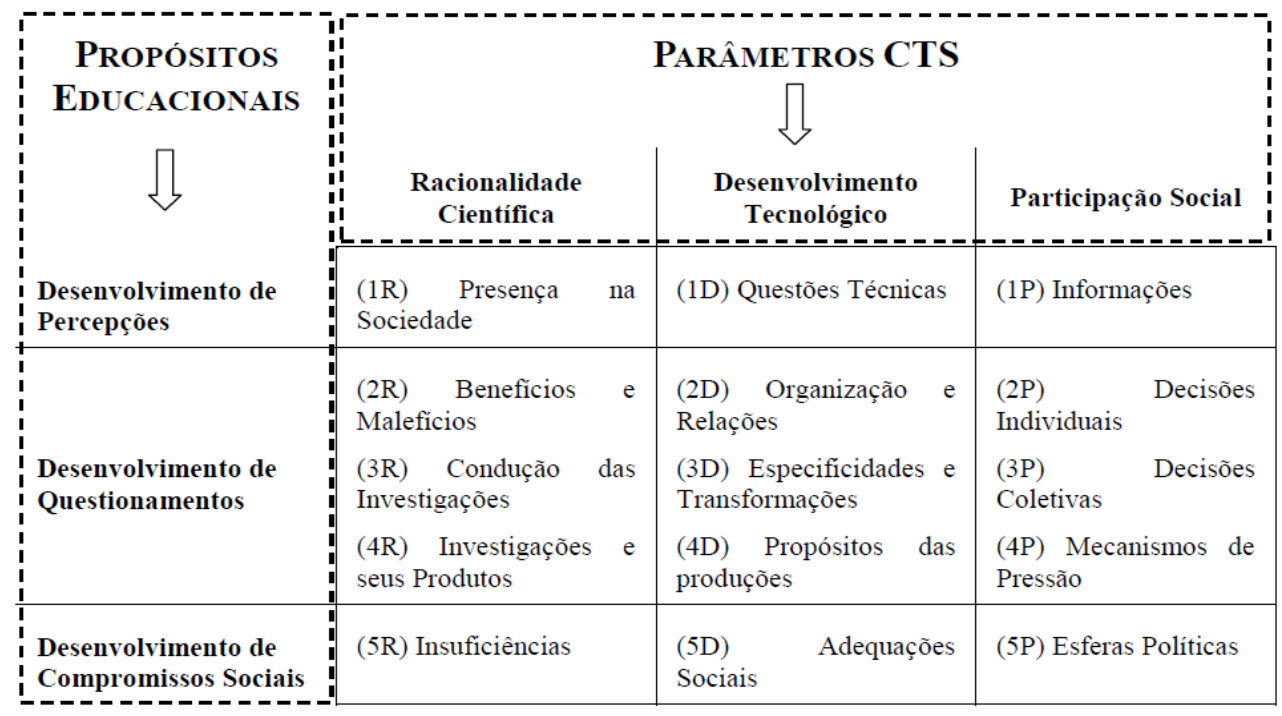

Figura 1 - Relação entre parâmetros e propósitos da educação CTS

Fonte: Elaboração própria

\section{Considerações finais}

Buscou-se, neste trabalho, contribuir para o universo de discussões que buscam compreender a polissemia e a identidade da educação CTS no contexto brasileiro do ensino de Ciências. Partiu-se do pressuposto de que a presença de diferentes abordagens e compreensões requer uma sistematização para além de uma simples classificação. Nesse sentido, optou-se pelo desenvolvimento de uma caracterização das propostas CTS, com a intenção de mapear abordagens, sentidos e perspectivas, além de potencialidades e espaços de atuação. Com isso, pretendeu-se desenvolver instrumentos para favorecer o diálogo e contribuir para um avanço das discussões sobre CTS na educação científica.

Como ponto de partida, constatou-se que há diferentes perspectivas educacionais e diferentes maneiras de abordar as relações CTS. A diversidade de perspectivas educacionais já vem sendo apontada por pesquisadores da área. A diversidade de olhares para as relações CTS, por sua vez, não tem sido foco de equivalente atenção em trabalhos e eventos da área; dando a entender, muitas vezes, que se trata de um consenso, bem definido, no âmbito do campo CTS.

Esses aspectos foram, então, utilizados como a base, ou os eixos, de uma matriz de referência. Em função disso, articularam-se diferentes frentes de análise, que levaram à definição de duas dimensões e suas caracterizações. Uma delas, associada aos parâmetros da educação CTS (racionalidade científica, desenvolvimento tecnológico e participação social) e a outra aos propósitos educacionais envolvidos (percepções, questionamentos e compromissos sociais).

Ressalta-se que esses propósitos e parâmetros devem ser entendidos como complementares em termos de formação científica, correspondendo a diferentes situações, contextos escolares e possibilidades de atuação, ou mesmo, a momentos sucessivos de 
apropriação de intenções. Essa afirmação concorda com o que foi mencionado anteriormente: nem sempre, a polissemia do campo CTS está associada à compreensão dos pesquisadores, mas aos espaços que o mesmo tem para desenvolver suas propostas.

Em síntese, essa investigação permitiu, por um lado, a construção de uma matriz, que serve de referência para localizar as diversas abordagens CTS presentes na educação científica, no Brasil. Por outro lado, permitiu resgatar lacunas e discussões que acabaram sendo esquecidas ao longo da trajetória das pesquisas sobre CTS desenvolvidas nesse contexto.

Associado a isso, merece destaque a carência de uma discussão atualizada de aspectos da função social da ciência no campo CTS - Ensino de Ciências. De certa forma, quando as preocupações CTS repercutiram para o campo da educação em ciências, aparentemente mantiveram um status mais ou menos inalterado ao longo das décadas seguintes, genericamente reconhecido como uma crítica a possíveis impactos negativos do desenvolvimento científico e tecnológico em relação à sociedade ou ao ambiente. No entanto, as discussões sobre as articulações e relações da CT com o espaço social têm ganhado novos aprofundamentos, discussões essas pouco incorporadas no âmbito educacional. A nosso ver, e considerando a matriz elaborada, essa atualização perpassa por considerar, por exemplo, visões mais críticas sobre racionalidade científica, desenvolvimento tecnológico e participação social.

Da mesma forma, muitas vezes, as intenções educacionais presentes nos trabalhos, acabam seguindo discursos estabelecidos, a exemplo da formação para a cidadania, para a tomada de decisão, para a responsabilidade social, etc.; sem, contudo, esclarecer o real sentido desses propósitos. Isso possivelmente está associado à ausência de referencias do campo da educação, causando um esvaziamento no discurso e nos propósitos das abordagens CTS. Nesse sentido, destaca-se que é importante definir, qual a intenção a ser seguida e almejada, ainda que, na prática ela não seja alcançada.

Diante dessas considerações, a caracterização apresentada não deve ser entendida como mais uma maneira de classificar trabalhos CTS. Sua contribuição, para além das já mencionadas, está relacionada à possibilidade de reconhecimento das diferentes dimensões que estão sendo ou que podem vir a ser contempladas em propostas CTS. Esse reconhecimento, ao mesmo tempo em que permite uma compreensão maior e mais clara sobre os sentidos e perspectivas das abordagens CTS no contexto brasileiro da educação científica, contribui para a definição/seleção de elementos a serem priorizados em práticas escolares.

Em particular, pretende-se que esse quadro possa fornecer referências em que os trabalhos e propostas possam situar-se, reconhecendo suas especificidades. Ao mesmo tempo, acredita-se que, por meio dessa sistematização, seja possível ampliar o conjunto de 
possibilidades das abordagens CTS. Dito de outra forma, essa matriz de abordagens permite reconhecer e situar intenções e, além disso, buscar coerência entre as próprias considerações. A partir dela, pode ser possível explicitar razões para as escolhas, encaminhamentos, limites e potencialidades de diferentes propostas CTS. Porém, vale ressaltar, não se trata de um instrumento para encaminhar as melhores práticas ou os melhores materiais CTS, uma vez que esses correspondem necessariamente a uma diversidade de contextos e objetivos. Esperase, ao contrário, que possa ser um instrumento relevante para refletir sobre essas práticas e suas articulações com os discursos, aspecto a ser aprofundado em investigações futuras.

\section{Referências}

AIKENHEAD, G. STS Education: A Rose by Any Other Name. In: CROSS, R. (Ed.): A Vision for Science Education: Responding to the work of Peter J. Fensham. New York: Routledge Falmer, 2003. p. 59-75.

AMORIM, A. C. O Ensino de Biologia e as Relações entre C/T/S: o que dizem os professores e o currículo do Ensino Médio? Dissertação de Mestrado em Educação - Universidade Estadual de Campinas, Campinas, 1995.

AMORIN, A.C. O que foge do olhar das reformas curriculares: nas aulas de Biologia o professor como escritor das relações entre Ciência, Tecnologia e Sociedade. Ciência \& Educação, v.7, n.1, p. 47-65, 2001.

ANGOTTI, J.A.; AUTH, M. Ciência e Tecnologia: implicações sociais e o papel da educação. Ciência \& Educação, v.7, n.1, p. 15-27, 2001.

ANGOTTI, J.A; BASTOS, F.; MION, R. Educação em Física: discutindo Ciência-Tecnologia e Sociedade. Ciência \& Educação, v.7, n.2, p. 183-197, 2001.

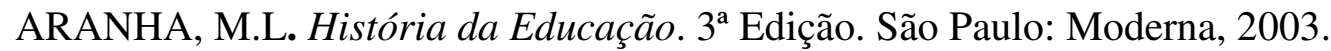

AULER, D. Interações entre Ciência-Tecnologia-Sociedade no Contexto da Formação de Professores de Ciências. Tese de Doutorado em Educação - Universidade Federal de Santa Catarina, Florianópolis, 2002.

AULER, D. Novos caminhos para a educação CTS: ampliando a participação. In: SANTOS, W.; AULER, D. (org.). CTS e educação científica: desafios, tendências e resultados de pesquisas. Brasília: Editora Universidade de Brasília, 2011. p. 73-97.

AULER, D.; BAZZO, W. A. Reflexões Para a Implementação do Movimento CTS no Contexto Educacional Brasileiro. Ciência \& Educação, v. 7, n.1, p. 1-13. Bauru, 2001.

AULER, D.; DELIZOICOV, D. Alfabetização científico-tecnológica para quê? Ensaio Pesquisa em Educação em Ciências, v. 3, n. 2, p. 1-13, 2001.

BAUMGARTEN, M. Conhecimento e sustentabilidade: política de ciência, tecnologia e inovação no Brasil contemporâneo. Porto Alegre: Editora da UFRGS/Editora Sulina, 2008.

BECK, U. A. Sociedade de Risco. São Paulo: Editora 34, 2010. 
BERNARDO, J.R.R. da; SILVA, V.H.D. da; FONTOURA, H.A. da; VIANNA, D.M. A construção do conceito de potência como um conceito universal de Física. In: ENCONTRO NACIONAL DE PESQUISA EM EDUCAÇÃO EM CIÊNCIAS, 5., Bauru. Anais... Bauru, 2005.

BORDENAVE, J. D. O que é Participação? 8a Edição. São Paulo: Brasiliense, 1994.

BOURDIEU, P. Os usos sociais da ciência: por uma sociologia cínica do campo científico. São Paulo: Editora UNESP, 2004.

BRASIL. Ministério da Educação. Secretaria de Educação Média e Tecnológica. PCN Ensino Médio: Ciências da Natureza, Matemática e suas Tecnologias. Brasília: MEC, 1998.

CACHAPUZ, A.; PAIXÃO, F.; LOPES. J. B.; GUERRA, C. Do estado da arte da pesquisa em educação em ciências: linhas de pesquisa e o caso Ciência-Tecnologia-Sociedade. Alexandria Revista de Educação em Ciência e Tecnologia, v.1, n.1, p. 27-49, 2008.

CRUZ, S. M. S. Aprendizagem centrada em eventos: uma experiência com enfoque Ciência, Tecnologia e Sociedade no Ensino Fundamental. Tese de Doutorado em Educação Universidade Federal de Santa Catarina, Florianópolis, 2001.

DAGNINO, R. A relação universidade-empresa no Brasil e o "argumento da hélice tríplice". Revista Brasileira de Inovação. v. 2, n. 2, p. 267-307, jul./dez. 2003.

DAGNINO, R. Ciência e Tecnologia no Brasil: o processo decisório e a comunidade de pesquisa. Campinas: Editora da Unicamp, 2007.

DAGNINO, R. As Trajetórias dos Estudos sobre Ciência-Tecnologia-Sociedade e da Política Científica e Tecnológica na Ibero-América. Alexandria - Revista de Educação em Ciência e Tecnologia, v.1, n.2, p.3-36, jul. 2008a.

DAGNINO, R. Neutralidade da Ciência e Determinismo Tecnológico: um debate sobre a tecnociência. Campinas: Editora da Unicamp, 2008b.

DAGNINO, R.; THOMAS, H.; DAVYT, A. El Pensamiento em Ciencia, Tecnología y Sociedad em Latinoamérica: uma interpretación política de su trayectoria. In: DAGNINO, R.; THOMAS, H. Ciência, Tecnologia e Sociedade: uma reflexão latino-americana. Taubaté: Cabral Editora e Livraria Universitária, 2003. p. 51-95.

DELIZOICOV, D. Pesquisa em Ensino de Ciências como ciências humanas aplicadas. Caderno Brasileiro de Ensino de Física. v.21, p.145-175, ago. 2004.

DELIZOICOV, D.; ANGOTTI, J. A. Metodologia do ensino de ciências. São Paulo: Cortez, 1990.

DUSEK, V. Filosofia da Tecnologia. São Paulo: Edições Loyola, 2009.

FEENBERG, A. O que é filosofia da tecnologia? In: NEDER, R. (org.) Andrew Feenberg: racionalização democrática, poder e tecnologia. Brasília: Centro de Desenvolvimento Sustentável/UnB, 2010. p. 39-51.

FREIRE, P. Extensão ou Comunicação? 4ª ed. Rio de Janeiro: Paz e Terra, 1979. 
FREIRE, P. Educação como prática de liberdade. Rio de Janeiro: Paz e Terra, 1982.

FREIRE, P. Pedagogia do Oprimido. 17ª ed. Rio de Janeiro: Paz e Terra, 1987.

FREIRE, P. Pedagogia da Indignação: cartas pedagógicas e outros escritos. São Paulo: Editora UNESP, 2000.

FREIRE, P. Conscientização: teoria e prática da libertação: uma introdução ao pensamento de Paulo Freire. São Paulo: Cortez \& Moraes, 2006.

FREITAS, M. C.; BICCAS, M. S. História Social da Educação no Brasil (1926 - 1996). São Paulo: Cortez, 2009.

GADOTTI, M. Histórias das Idéias Pedagógicas. São Paulo: Ática, 1995.

GARCÍA, M. I. G.; CEREZO, J. A.L.; LUJÁN, J. L. Ciência, tecnologia y sociedad. Una introducción al estudio social de la ciencia y la tecnología. Madrid: Tecnos, 1996.

GOUVÊA, G.; LEAL, M.C. Uma visão comparada do ensino em Ciência, tecnologia e Sociedade na Escola e em um Museu de Ciência. Ciência \& Educação, v.7, n.1, p.67-84, 2001.

HERRERA, A. Novo enfoque do desenvolvimento e o papel da ciência e da tecnologia. In: DAGNINO, R.; THOMAS, H. Ciência, Tecnologia e Sociedade: uma reflexão latinoamericana. Taubaté: Cabral Editora e Livraria Universitária, 2003. p. 25-45.

HUNSCHE, S.; DALMOLIN, A.M.T.; ROSO, C.C.; SANTOS, R.A.; AULER, D. Enfoque CTS no contexto brasileiro: Caracterização segundo periódicos da área de educação em ciências. In: ENCONTRO NACIONAL DE PESQUISA EM EDUCAÇÃO EM CIÊNCIAS, 7., Florianópolis. Anais..., Florianópolis, 2009.

JAPIASSU, H. Ciência e destino humano. Rio de Janeiro: Himago, 2005.

KRASILCHIK, M. Professor e o currículo das ciências. São Paulo: EPU/EDUSP, 1987.

KUHN, T. A estrutura das revoluções científicas. São Paulo: Perspectiva, 1962.

LACEY, H. Valores e atividade científica 2. São Paulo: Associação Filosófica Scientiae Studia/Editora 34, 2010.

LATOUR. B.; WOOLGAR, S. A vida de laboratório - a produção de fatos científicos. Rio de Janeiro: Relume Dumará. 1979.

LEYDESDORFF, L.; ETZKOWITZ, H. The transformation of university-industrygovernment relations. Eletronic Journal of Sociology, v. 5, n.4, p.1-17, 2001.

LINSINGEN, I. Perspectiva educacional CTS: aspectos de um campo em consolidação na América Latina. Ciência \& Ensino, vol. 1, número especial, novembro de 2007.

MARTINS, I.P. (Org.) O Movimento CTS na Península Ibérica. Aveiro: Universidade de Aveiro, 2000. 
MEGID NETO, J. Tendências da pesquisa acadêmica sobre o ensino de ciências no nível fundamental. Tese de Doutorado em Educação - Universidade Estadual de Campinas, Campinas, 1999.

MITCHAM, C. Thinking Through Technology, The Path Between Engineering and Philosophy, Chicago: University of Chicago Press, 1994.

MORAES, R.; GALLIAZZI, M. do C. Análise Textual Discursiva. Ijuí: Unijuí, 2007.

MORAIS, R. de. Evoluções e revoluções da ciência. Campinas: Alinea Editora, 2007. MORIN, E. Ciência com consciência. $8^{\text {a }}$ ed. - Rio de Janeiro: Bertrand Brasil, 2005.

MORIN, E. Educar na era planetária: o pensamento complexo como método de aprendizagem no erro e na incerteza humana. São Paulo: Cortez, Brasília: UNESCO, 2009.

MORIN, E. Rumo ao abismo? Ensaio sobre o destino da humanidade. Rio de Janeiro: Bertrand Brasil, 2011.

OLIVEIRA, M.B. Desmercantilizar a tecnociência. In: SANTOS, B. S. (org.). Conhecimento prudente para uma vida decente: "Um discurso sobre as ciências" revisitado. Porto, Edições Afrontamento, 2003.

PEDRETTI, E.; NAZIR, J. Currents in STSE Education: Mapping a Complex Field, 40 Years On. Science Education, v. 95, n. 4, p. 601-626, Jul. 2011.

PINHEIRO, N.A.M.; SILVEIRA, R.M.; BAZZO, W.A. Ciência, Tecnologia e Sociedade: a relevância do enfoque CTS para o contexto do Ensino Médio. Ciência \& Educação, v.13, n.1, p.71-84, 2007.

PINTO, A. V. O conceito de tecnologia. Rio de Janeiro: Contraponto, 2005.

POPPER. K. Conjecturas e Refutações. Brasília: Editora UnB, 2a edição, 1982.

SALEM, S. Perfil, evolução e perspectivas da pesquisa em ensino de física no Brasil. Tese de Doutorado em Ciências/Ensino de Física - Universidade de São Paulo, São Paulo, 2012.

SANTOS, B.S. Um discurso sobre as Ciências. 15ª ed. Porto: Edições Afrontamento, 2007.

SANTOS, M.E.V.M. dos. A cidadania na voz dos manuais escolares. Lisboa: Livros Horizonte, 2001.

SANTOS, W.L.P. O ensino de química para formar o cidadão: principais características e condições para a sua implantação na escola secundária brasileira. Dissertação de Mestrado em Educação - Universidade Estadual de Campinas, Campinas, 1992.

SANTOS, W.L.P. Educação científica na perspectiva de letramento como prática social: funções, princípios e desafios. Revista Brasileira de Educação, v. 12, n. 36, p. 474-492, set/dez. 2007.

SANTOS, W.L.P. Educação Científica Humanística em Uma Perspectiva Freireana: Resgatando a Função do Ensino de CTS. Alexandria Revista de Educação em Ciência e Tecnologia, v.1, n.1, p. 109-131, mar. 2008. 
SANTOS, W.L.P. Significados da Educação Científica com enfoque CTS. In: SANTOS, W.L.P.; AULER, D. (org.). CTS e educação científica: desafios, tendências e resultados de pesquisas. Brasília: Editora Universidade de Brasília, 2011. p. 21-47.

SANTOS, W.L.P.; MORTIMER, E. F. Uma análise de pressupostos teóricos da abordagem C-T-S (Ciência, Tecnologia e Sociedade) no contexto da educação brasileira. Ensaio. v. 2, n. 2, p. 1-23, dez. 2002.

SAVIANI, D. História das Idéias Pedagógicas no Brasil. São Paulo: Autores Associados, 2008.

SHINN, T.; RAGOUET, P. Controvérsias sobre a ciência. São Paulo: Editora 34, 2008. SILVA, T. T. da. Documentos de Identidade: uma introdução às teorias do currículo. $3^{\mathrm{a}} \mathrm{ed}$. Belo Horizonte: Autêntica, 2010.

SOUZA, R.G; ALENCAR, J.R.S. Avaliando uma proposta de ensino através de temas sociais e prática CTS: O motor à combustão. In: ENCONTRO NACIONAL DE PESQUISA EM ENSINO DE CIÊNCIAS, 6., Florianópolis. Anais... Florianópolis, 2007.

STRIEDER, R.B.; KAWAMURA, M.R.D. Panorama das pesquisas pautadas por abordagens CTS. In: ENCONTRO NACIONAL DE PESQUISA EM ENSINO DE CIÊNCIAS, 7., Florianópolis. Anais... Florianópolis, 2009.

STRIEDER, R.B.; KAWAMURA, M.R.D. Pesquisas sobre o Estado da Arte em CTS: Aproximações e Contrapontos. In: ENCONTRO DE PESQUISA EM ENSINO DE FÍSICA, 12., Águas de Lindóia. Anais... Águas de Lindóia, 2010.

STRIEDER, R.B.; KAWAMURA, M.R.D. Discussões sobre CTS no âmbito da Educação em Ciências: parâmetros e enfoques. In: ENCONTRO NACIONAL DE PESQUISA EM ENSINO DE CIÊNCIAS, 8., Campinas. Anais... Campinas, 2011.

STRIEDER, R.B. Abordagens CTS na educação científica no Brasil: sentidos e perspectivas. Tese de Doutorado em Ciências/Ensino de Física - Universidade de São Paulo, São Paulo, 2012.

STRIEDER, R.B.; KAWAMURA, M.R.D. Abordagens CTS e racionalidade científica: diferentes perspectivas. In: ENCONTRO DE PESQUISA EM ENSINO DE FÍSICA, 13., São Sebastião. Anais... São Sebastião, 2012.

STRIEDER, R.B.; KAWAMURA, M.R.D. Perspectivas de participação social no âmbito da educação CTS. Uni-pluri/versidad, v. 14, n. 2, p. 101-110, 2014.

TAVARES, D. D.; SOARES, T.C. Cinemática segundo a perspectiva do movimento CTS. In: ENCONTRO NACIONAL DE PESQUISA EM ENSINO DE CIÊNCIAS, 5., Bauru. Anais... Bauru, 2005.

TRIVELATO, S. L. F. C/T/S: Mudanças Curriculares e Formação de Professores. Tese de Doutorado em Educação - Universidade de São Paulo, São Paulo, 1993.

VANNUCCHI, A. I. História e Filosofia da Ciência: da teoria para a sala de aula. Dissertação de Mestrado em Ciências/Ensino de Física - Universidade de São Paulo, São Paulo, 1996. 


\section{SOBRE AS AUTORAS}

ROSELINE BEATRIZ STRIEDER. É licenciada em Física pela Universidade Federal de Santa Maria, mestre e doutora em Ciências/Ensino de Física pelo Programa de Pós-Graduação Interunidades em Ensino de Ciências da Universidade de São Paulo. É professora do Instituto de Física e do Programa de Pós-graduação em Ensino de Ciências da Universidade de Brasília. Possui interesse por temáticas associadas à CTS, Abordagem Temática Freireana, dentre outras.

MARIA REGINA DUBEUX KAWAMURA. É professora do Instituto de Física e do Programa de Pós-graduação Interunidades em Ensino de Ciências da Universidade de São Paulo. Possui interesse por temáticas associadas à CTS, meio ambiente, divulgação científica, dentre outras.

Recebido: 19 de janeiro de 2016.

Revisado: 16 de maio de 2016.

Aceito: 02 de agosto de 2016. 